Jonas Wäschle

\title{
Die internationale Zuständigkeit für Schadensersatzklagen gegen Weltkartelle
}

\author{
Koordination der Gerichtspflichtigkeit in Europa und den USA
}

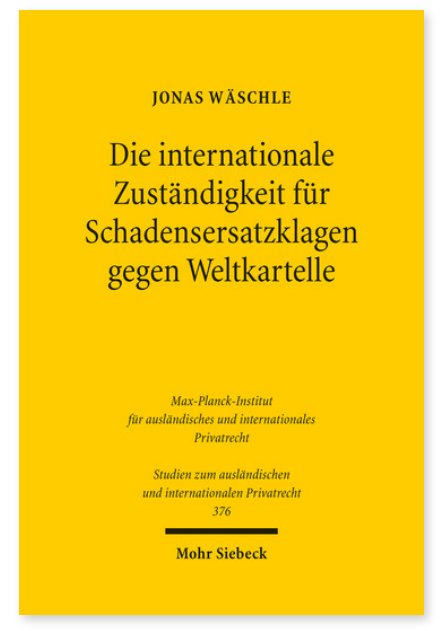

2017. XX, 268 Seiten. StudIPR 376

ISBN 978-3-16-155249-6

DOI 10.1628/978-3-16-155249-6

eBook PDF 79,00€

ISBN 978-3-16-155017-1

fadengeheftete Broschur 79,00€
Kartellrecht wird in jüngster Zeit in Europa vermehrt mit den Mitteln des Privatrechts durchgesetzt. Bei global agierenden Kartellen steht den Geschädigten für Schadensersatzklagen gegen die Beteiligten des Kartells häufig eine Vielzahl potenzieller Gerichtsstände zur Verfügung. Dabei kommt dem Gerichtsstand für den Ausgang derartiger Verfahren eine erhebliche praktische Bedeutung zu. Jonas Wäschle untersucht die internationale Zuständigkeit für Kartellschadensersatzklagen anhand des deutschen und US-amerikanischen Rechts. Aufbauend auf den gewonnenen Erkenntnissen werden Möglichkeiten ausgelotet, wie die Handhabung der internationalen Zuständigkeit bei Weltkartellen im deutsch-amerikanischen Rechtsverkehr koordiniert werden kann.

Jonas Wäschle Geboren 1986; Studium der Rechtswissenschaft in Heidelberg und Aberdeen (LL.M.); Forschungsaufenthalt an der New York School of Law (NYU); Promotionsstipendien der Studienstiftung des deutschen Volkes und des Max-PlanckInstituts für Innovation und Wettbewerb in München; 2016 Promotion; derzeit Rechtsreferendar am Oberlandesgericht München.
Jetzt bestellen:

https://mohrsiebeck.com/buch/die-internationale-zustaendigkeit-fuer-schadensersatzklagen-gegen-weltkartelle9783161552496?no_cache=1

order@mohrsiebeck.com

Telefon: +49 (0)7071-923-17

Telefax: $+49(0) 7071-51104$ 